\title{
ASTIGMATISM IN BANGLADESHI AND WHITE SCHOOL ENTRANTS IN EAST LONDON: A PROSPECTIVE COMPARATIVE STUDY
}

\author{
J. R. FULLER, L. A. BAXTER, S. HARUN and I. S. LEVY \\ London
}

\section{SUMMARY}

A prospective comparative study was undertaken to determine the prevalence of significant astigmatism in school entrants living in the same area of East London. Thirty-one Bangladeshi and thirty-one white school entrants were refracted in two local state schools. In the Bangladeshi group, 7 right and 5 left eyes had more than 1 dioptre of astigmatism. Most of this astigmatism was with the rule. In the white group, 1 left eye had more than 1 dioptre of astigmatism. This study has shown a statistically significant incidence of astigmatism in an ethnic group in East London. This difference between two racial groups living in the same area of East London has not previously been documented. In our study, Bangladeshi school entrants may be at greater risk of amblyopia if their refractive error is not identified and corrected.

The Royal Hospital NHS Trust is situated in East London and serves a large Bangladeshi community. Visual acuity assessment is normally undertaken by school nurses in Tower Hamlets, and children are referred to the eye department at the hospital with vision of $6 / 12$ or less in one or both eyes. At the hospital a full orthoptic assessment and mydriatic refraction are undertaken. There was a clinical impression within the department that significant astigmatism was more common in Bangladeshi children. A detailed clinical audit of these children supported this clinical impression. Based on these findings a prospective comparative study between Bangladeshi and white school entrants was undertaken consisting of a full orthopic assessment and non-mydriatic refraction to determine the prevalence of astigmatism in these two racial groups. Only the astigmatism found is considered in this paper.

Correspondence to: Mrs L. A. Baxter, Head Orthoptist, Department of Ophthalmology, Royal London NHS Trust, Whitechapel, London E1 1BB, UK.

\section{METHODS}

Two local state-funded schools were visited and complete reception classes were assessed from each school. A reception class consists of the most recently admitted cohort of children. The children underwent an orthoptic assessment and non-mydriatic refraction. School A is almost exclusively attended by Bangladeshi children and the one reception class of 31 children was assessed. School B is predominantly attended by white children and the two reception classes totalling 40 children were assessed. To compare equal numbers of children and with no preselection, the first 31 white children tested were included in this study. In both schools the head teacher's permission was obtained and parental consent was given for screening. Visual acuity, cover test, ocular movements, convergence and Frisby stereo acuity was carried out by one of us (L.B.) and the non-mydriatic refraction was undertaken in identical clinical conditions by another (R.F.). Streak retinoscopy was performed at half a metre in a dimly lit room. The child's fixation was maintained with the help of an assistant. Cycloplegia was not used as astigmatism rather than spherical error was being investigated. A plus cylindrical lens convention was used. In this paper, only the cylindrical component of the refractive error will be considered. The astigmatism was considered to be with the rule if the plus cylinder was between 70 degrees and 110 degrees. If the axis of the plus cylinder was between 160 degrees and 20 degrees, against-the-rule astigmatism was considered to be present. If the axis fell at any other angle, oblique astigmatism was considered present.

\section{RESULTS}

The Bangladeshi children had a mean age of 5.7 years and the white children had a mean age of 6.0 years. In the Bangladeshi group 7 of the 31 right eyes 
Table I. Astigmatic values in 31 Bangladeshi and 31 white children

\begin{tabular}{|c|c|c|c|c|}
\hline \multirow[b]{2}{*}{ Astigmatic value } & \multicolumn{2}{|c|}{ Bangladeshi children } & \multicolumn{2}{|c|}{ White children } \\
\hline & Right eyes & Left eyes & Right eyes & Left eyes \\
\hline 0 & 10 & 13 & 23 & 18 \\
\hline 0.25 & 1 & 0 & 0 & 3 \\
\hline 0.5 & 9 & 8 & 5 & 5 \\
\hline 0.75 & 1 & 1 & 1 & 1 \\
\hline 1 & 3 & 4 & 2 & 3 \\
\hline 1.25 & 1 & 0 & 0 & 1 \\
\hline 1.5 & 2 & 2 & 0 & 0 \\
\hline 1.75 & 1 & 0 & 0 & 0 \\
\hline 2 & 2 & 1 & 0 & 0 \\
\hline 2.25 & 0 & 0 & 0 & 0 \\
\hline 2.5 & 0 & 0 & 0 & 0 \\
\hline 2.75 & 0 & 0 & 0 & 0 \\
\hline 3 & 1 & 2 & 0 & 0 \\
\hline$>3.0$ & 0 & 0 & 0 & 0 \\
\hline
\end{tabular}

$p$ value (two-tailed): right eyes, 0.0009 ; left eyes, 0.0283 .

and 5 of the 31 left eyes had more than 1 dioptre of astigmatism. Of the 7 right eyes, 4 had with-the-rule and 1 had oblique astigmatism. Of the 5 left eyes, 4 had with-the-rule, 2 had against-the-rule and 1 had oblique astigmatism. In the right eyes of the white group of children there were no cases of more than 1 dioptre of astigmatism. Only 1 of the 31 left eyes of the white children had more than 1 dioptre of astigmatism (Table I). Statistical comparison using a two-tailed Student's $t$-test between Bangladeshi right eyes and white right eyes, and between Bangladeshi left eyes and white left eyes, showed a $p$ value of less than 0.03 for both.

\section{DISCUSSION}

A number of authors suggest that astigmatism changes in the first few years of life. In a study of 276 infants under 1 year of age, $45 \%$ had more than 1 dioptre of astigmatism. ${ }^{1}$ Another study has shown that most infant astigmatism is naturally eliminated by 4 years of age. ${ }^{2}$ This suggests that school entrants with significant astigmatism will largely carry their refractive error with them into adult life. A study of children between the ages of 6 and 12 years showed that only $4-7 \%$ showed more than 0.75 dioptre of astigmatism, and suggested that there is no significant change in childhood astigmatism during the school years. ${ }^{3}$ In this study $97 \%$ of the children were white and few studies have directly compared astigmatism between racial groups. In our results only 1 eye of the white children aged 5-6 years had more than 1 dioptre of astigmatism, but approximately $20 \%$ of the Bangladeshi school entrants of the same age had more than 1 dioptre of astigmatism. A study of the ocular and visual profiles of native North American Indian tribes found $15 \%$ of some tribes and only $3 \%$ of others had more than 1 dioptre of astigmatism. ${ }^{4}$ No specific explanation was given for these differences.

A longitudinal study of changes in corneal astigmatism in Asian eyes found a greater magnitude in the rate of change of corneal astigmatism than had been previously reported in Caucasians. ${ }^{5}$ They suggest that anatomical differences in Asian eye lids cause the increased changes in astigmatism in Asian eyes. However, both racial groups within our study are Caucasian.

Our study has shown a significant difference in rate of significant astigmatism between racial groups in East London. The exact reason for the difference between Bangladeshi and white school entrants is not known. Astigmatism, like all other human characteristics, is dependent on the interplay of genetic and environmental influences. Clearly differences between racial groups depend not only on inheritance but on also environmental exposure which is more common in one racial group than another. It has been proposed that uncorrected astigmatism leads to amblyopia, and the earlier astigmatism is corrected then the more likely that amblyopia will be prevented. ${ }^{6}$ A 0.25 dioptre practical tolerance limit for uncorrected astigmatism has been suggested. ${ }^{7}$ Clearly relevant health professionals should be aware that there is a higher prevalence of astigmatism in certain racial groups. Finally, the increased workload of ophthalmic units serving the Bangladeshi community has implications for resource allocation.

We thank Professor S. Evans for help with the statistics.

Key words: Astigmatism, Amblyopia, Bangladeshi, Ethnic, White.

\section{REFERENCES}

1. Mohindra I, Held R, Gwiazda J, Brill S. Astigmatism in infants. Science 1978;202:329-30.

2. Gwiazda J, Scheiman M, Mohindra I, Held R. Astigmatism in children: changes in axis and amount from birth to six years. Invest Ophthalmol Vis Sci 1984;25:89-92.

3. Hirch MJ. Changes in astigmatism during the first eight 
years of school: the interim report from the Ojai longitudinal study. Am J Optom 1963;40:127.

4. Maples WL, Atcheley J, Ashby W, Ficklin B. An epidemiological study of the ocular and visual profiles of Oklahoma Cherokees and Minnesota Chippewas. J Am Optom Assoc 1990;61:784-8.

5. Kame RT, Jue TS, Shigekuni DM. A longitudinal study of corneal astigmatic changes in Asian eyes. J Am Optom Assoc 1993;64:215-9.

6. Rabinowitz IM. Amblyopia. In: Harley RD, editor. Pediatric ophthalmology. Philadelphia: WB Saunders, 1983:293-306.

7. Charman WN, Voisin L. Optical aspects of tolerance and uncorrected ocular astigmatism. Optom Vis Sci 1993;70:111-7. 